\title{
Significance of Nerve Excitability Tests in the Prognosis of Facial Paralysis in Leprosy*
}

\author{
M. A. FURNESS \\ Chief Physiotherapist \\ A. B. A. KARAT \\ Consultant Physician \\ Mrs. S. KARAT \\ Consultant Surgeon \\ Schieffelin Leprosy Research Sanatorium, Karigiri, Tamilnadu, S. India
}

\begin{abstract}
This study of the prognosis in 30 leprosy patients suffering from paralysis of the facial nerve, in which the response to electrical stimulation was employed as the prognostic factor, has shown that the likelihood of recovery depended on a positive response and was closely related to the duration of the paralysis - the shorter the duration, the greater the probability-and also that it was best in patients with lepromatous leprosy, less good in borderline cases, and least good in those with tuberculoid leprosy.
\end{abstract}

\section{INTRODUCTION}

The recognition of the nature of the nerve lesion is an important factor in the treatment of facial paralysis. Since prognosis is dependent on this factor, it is necessary to know whether the lesion is the result of segmental demyelination or destruction of axons. Several electrodiagnostic procedures such as nerve excitability tests, faradic-galvanic response, strength duration curves, and electromyography have been employed to elicit this information (Wynn Parry, 1961; Licht, 1962; Gilliatt, 1962). The present study demonstrates the prognostic significance of nerve-excitability tests in the management of facial paralysis in leprosy.

\section{HISTORICAL NOTE}

Electrodiagnosis of facial palsies was first described by Duchenne (1872), who distinguished between nerve-excitability tests and those based on local stimulation of individual muscles. $\mathrm{He}$ claimed that the investigations permit of distinction between those palsies which recover easily and rapidly and those which persist despite all methods of treatment. In the former,

Received for publication, 3 April, 1969.

* Paper read at the Eighth Biennial Conference of the Indian Association of Leprologists, 23 to 26 February, 1969, New Jelhi. muscular contraction on nerve stimulation was present, in the latter, absent. More recently (Aulick, 1967; Campbell et al., 1962) nerveexcitability tests have again been advocated, as they help to distinguish clearly between neuropraxia or a transient block in neuromuscular conduction (demyelinating lesions) and axonal degeneration.

\section{PRINCIPLES}

When a nerve is subjected to ischaemic and/or increased pressure, its ability to conduct nervous impulses is impaired over the affected segment of the nerve. This block, caused by segmental demyelination, is termed neuropraxia and the excitability of the nerve distal to the block remains unaffected. When damage of the axons occurs, the lesion is called an axonotomesis and the nerve loses its ability to conduct nervous impulses. The muscle then exhibits alterations in excitability, characteristic of the reaction of degeneration.

Motor nerve excitability is conveniently tested by applying an electrical stimulus to the nerve trunk distal to the suspected site of the lesion. The intensity of current necessary to produce minimal visible contraction of the muscles is compared with the intensity of stimulation needed on the unaffected side. 
INVOLVEMENT OF THE FACIAL NERVE

The facial nerve in leprosy may be involved at its point of emergence from the stylo-mastoid foramen or more commonly the zygomatic branch at the zygomatic arch (Brand, 1964). The nerve itself is affected by an inflammatory process and leprosy is perhaps the only disease in which the peripheral nerve is invaded by the causative organism (Editorial, 1967). In the hyperergic types, the cellular response is early and intense, and is often associated with inflammatory oedema and may result in the formation of an epithelioid cell granuloma which replaces the nerve bundles. There is therefore partial or complete destruction of axons which on occasion may result in complete fibrosis of the nerve. In the anergic types of leprosy, the cellular response is slow to develop and the axons remain well preserved for a long time (Editorial, 1967). These nerves tend to show a proliferation of perineural and endoneural connective tissue which may result in ischaemia and demyelination of the nerve.

\section{MATERIALS AND METHODS}

Thirty patients with unilateral facial paralysis attending the out-patient department of the Schieffelin Leprosy Research Sanatorium, Karigiri, were followed up for periods varying from 1 to 2 years. The distribution of cases according to classification is shown in Table 1 .

TABLE 1

\begin{tabular}{lrc}
\hline Classification & No. & $\%$ \\
\hline Lepromatous & 4 & 13 \\
Borderline & 20 & 67 \\
Tuberculoid & 6 & 20 \\
Total & 30 & 100 \\
\hline
\end{tabular}

All the patients showed evidence of paralysis of the zygomatic branch of the facial nerve, although in some cases there was involvement of other branches as well. Manual muscle tests, using the Medical Research Council 1 to 5 grading (M.R.C. Special Report Series, 1954), were employed to assess power in the facial muscles. All the patients were receiving regular medical management with anti-leprosy and/or anti-inflammatory drugs at various periods during the study.

The facial nerve was stimulated by applying the active electrode (cathode) to a point below the mastoid process and behind the angle of the jaw. The zygomatic branch was then stimulated over the zygomatic arch, near the lateral canthus of the eye. During this procedure the indifferent electrode (anode) was placed over the cervical spine. To localize the stimulus and to avoid unwanted contraction of other muscle groups, the active electrode was small and measured approximately 1 square $\mathrm{cm}$. The indifferent electrode was large, being 150 square $\mathrm{cm}$. in area. A square wave pulse of $1 \mathrm{msec}$ duration and 50 pulses per second was delivered from a constant voltage, R.A.F. Type 2, electronic stimulator. The unaffected side was tested first and the minimal current intensity noted, the active electrode being moved around until the site of greatest response was found. This method of stimulation was then repeated on the affected side and the current intensities carefully recorded.

Where increased currents were used on the affected side, care was taken that contraction of the masseter muscle was not mistaken for response of the facial mucles. Minor variations in current intensities occurred between the 2 sides in normal individuals and we have therefore regarded an increase of more than $2 \mathrm{v}$ as an indication of impairment in nerve excitability.

The results obtained were classified as follows:

(a) Excitability unimpaired: the affected nerve responded at the same current intensity as the normal nerve.

(b) Excitability diminished: the affected nerve responded fully but required more current than the normal.

(c) Excilability absent: the nerve failed to respond, regardless of how much current was applied. 
Recovery was also classified into 3 grades:

(1) Complete: that is, full volitional activity and the absence of distortion at rest or on contraction and the orbicularis occuli graded 5 .

(2) Partial: volitional activity present, face normal in repose, some distortion or asymmetry on attempting facial movements. The eye can be fully shut by volition but the orbicularis occuli is graded 3 .

(3) Poor: distortion at rest and on attempted contraction. The palpebral fissure remains open and the orbicularis occuli is graded 0 .

\section{RESULTS}

TABLE 2

\begin{tabular}{lrrrrrrr}
\hline $\begin{array}{l}\text { Nerve } \\
\text { excitability }\end{array}$ & No. & \multicolumn{2}{c}{$\begin{array}{c}\text { Complete } \\
\text { No. }\end{array}$} & $\%$ & \multicolumn{2}{c}{$\begin{array}{c}\text { Pecovery } \\
\text { Partial }\end{array}$} & \multicolumn{2}{c}{$\begin{array}{c}\text { Poor } \\
\text { No. }\end{array}$} & No. & $\%$ \\
\hline $\begin{array}{l}\text { Unimpaired } \\
\text { Diminished }\end{array}$ & 12 & 8 & 100 & & & & \\
Absent & 10 & & - & - & & 10 & 100 \\
\hline
\end{tabular}

Table 2 shows the number of cases according to the 3 electrodiagnostic groups and the degree of recovery in each group. The 8 patients in whom nerve excitability was unimpaired showed complete recovery, 10 patients with no recordable nerve excitability showed poor recovery, while in the intermediate group of 12 patients in whom nerve excitability was diminished, complete recovery was recorded in one case and partial recovery in $7(58 \%)$, but in 4 cases $(33 \%)$ no recovery was observed.

Table 3 shows the difference in threshold stimulus in the normal and affected sides in the
TABLE 3

\begin{tabular}{ccl}
\hline $\begin{array}{c}\text { No. of } \\
\text { cases }\end{array}$ & $\begin{array}{c}\text { Average difference } \\
\text { in threshold }(\mathrm{v})\end{array}$ & Recovery \\
\hline 1 & 5 & Complete \\
7 & 10.5 & Partial \\
4 & 16.3 & Poor \\
\hline
\end{tabular}

group of 12 patients who showed diminished nerve excitability (Table 1 ). In the one patient in whom the difference in threshold stimulus was $5 \mathrm{v}$, complete recovery occurred. In 7 cases with an average difference of $10.5 \mathrm{v}$ in threshold stimulus partial recovery was noted, and in 4 cases in which the average difference was $16.3 \mathrm{v}$ a poor recovery was recorded.

Table 4 correlates nerve excitability with recovery, according to duration of the paralysis. Nerve excitability remained unimpaired in the majority of cases $(87.5 \%)$ when the duration of paralysis was 3 months or less. Unimpaired excitability was seen in one case with a paralysis of 3 to 6 months' duration. Recovery was complete in both groups. In the diminished nerve excitability group, 3 cases $(25 \%)$ showed some recovery within 3 months, 5 in 3 to 6 months, and 4 in 6 to 12 months. Only one patient made a complete recovery in the first group, $5(42 \%)$ made a partial recovery in the second, and $4(33 \%)$ poor recovery in the third. Nerve excitability was found to be progressively impaired as the duration of the paralysis increased and the chance of recovery was poor in this group.

TABLE 4

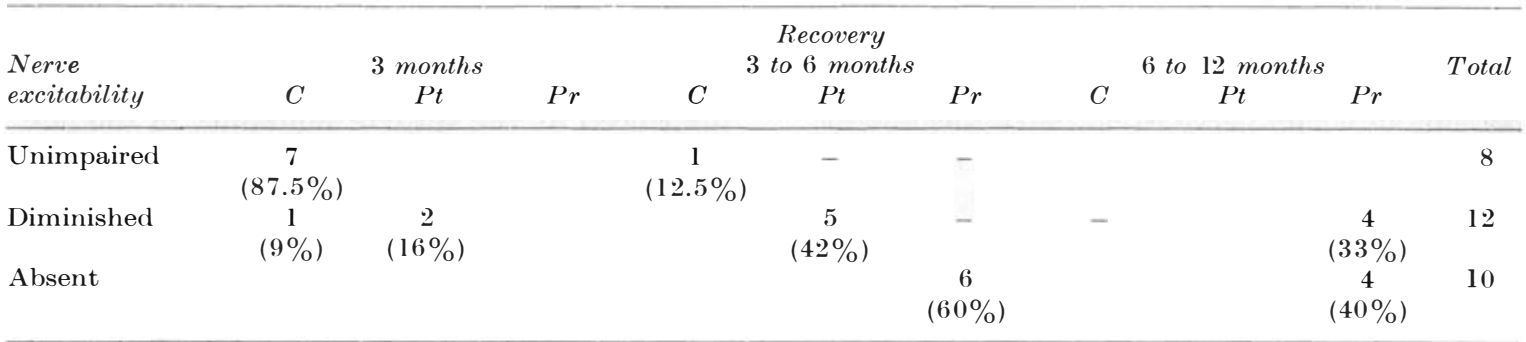


TABLE 5

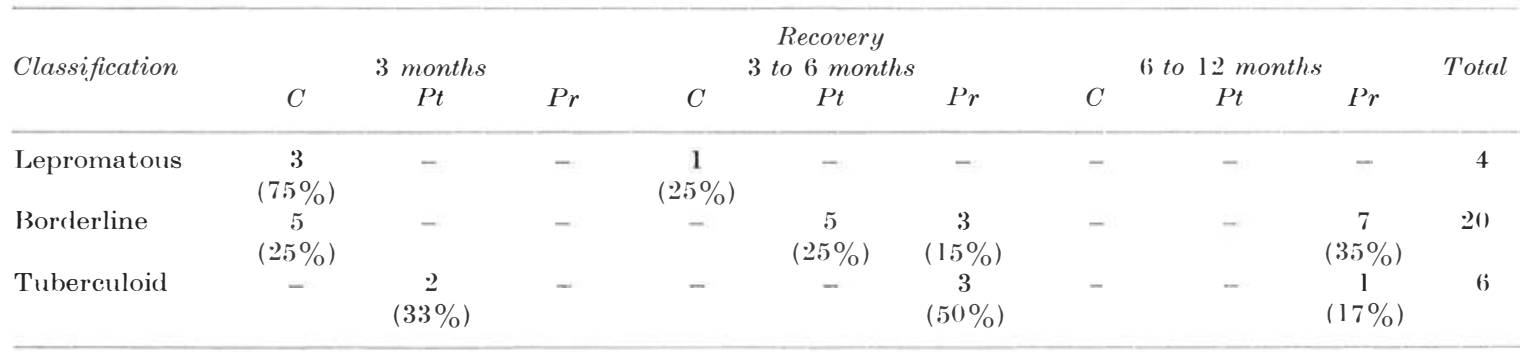

C, complete; Pt, partial; Pr, poor.

Table 5 correlates classification with recovery according to duration of paralysis. In cases of lepromatous leprosy, the recovery was complete in all cases $(100 \%)$, even in the one case where the duration of paralysis was 3 to 6 months. In the borderline group, recovery was complete in 5 cases $(25 \%)$ after 3 months duration of paralysis. As the duration extended, recovery tended to be partial in the 3 to 6 months group, and poor in the 6 to 12 months group. Of the 6 patients with tuberculoid leprosy, $4(67 \%)$ in the longer duration groups showed a poor recovery, and recovery was only partial in the 2 patients in the short duration group.

\section{DISCUSSION}

These results show that patients with neuropraxia as judged by retention of nerve excitability have an excellent chance of recovery. This is probably because the lesion is in the nature of a segmental demyelination. Since the neuropraxia in leprosy may last for a relatively long time (Licht, 1962), it is necessary that these patients have adequate treatment to reduce inflammation in the nerves and be instructed to perform facial exercises.

It is also significant that in the group of patients in whom nerve excitability was absent, no recovery was recorded. This finding is probably an indication of extensive axonal degeneration. After a period of time, all patients in this group needed a temporalis muscle transfer operation or tarsorrhaphy to provide closure of the eye and protection of the cornea.
In the intermediate group with diminished excitability and partial axon damage it is interesting to note that recovery was complete in only one patient, and that in the 7 patients in whom full closure of the eye was obtained the orbicularis occuli was only graded 3 plus by manual muscletests. It would seem pertinent to observe that in this category of patients the chance of recovery is greater when the difference in the threshold stimulus between the normal and affected sides is small. All patients in this group who showed partial recovery were advised to perform conventional facial exercises to maintain the nutrition of denervated muscles and to provide compensatory closure of the eye. In 4 patients in whom recovery was poor, tarsorrhaphy or tendon transfers were employed to protect the cornea.

It would appear that there is a significant correlation in the 3 electrodiagnostic groups between recovery and the duration of paralysis (Table 5). The shorter the duration of paralysis, the greater is the possibility for retention of nerve excitability and therefore of a good prognosis; but the longer the duration of paralysis, the more likely it is to produce absence of nerve excitability and hence a poor prognosis. Recovery also appears to be considerably influenced by the state of immunity of the host and therefore the type of leprosy the patient has and the duration of paralysis (Table 5). The chances of recovery seem to be best in lowresistant lepromatous leprosy, less in the borderline type, and least in the high-resistant tuberculoid types of leprosy. In all types of 
leprosy, the shorter the duration of paralysis, the greater the chances of recovery.

Under the conditions of this study of patients with facial-nerve paralysis, the treatment status in terms of specific anti-leprosy therapy (DDS, thiosemicarbasone) as well as anti-inflammatory drugs (prednisolone, chloroquine) did not appear to alter to any great extent the prognosis for recovery. From the limited number of cases studied it appears as though the primary determinants of prognosis are: (1) type of leprosy; (2) duration of the paralysis; and (3) the responses to electrical stimulation of the affected nerve. The role of specific therapeutic measures is now under a long-term investigation. It is hoped that further data in this regard will be available at a later date.

\section{SUMMARY}

A test of motor nerve excitability has been used to study 30 leprosy patients with facial paralysis. It has been demonstrated that when nerve excitability is unimpaired, the prognosis for recovery is good. When it is absent, the prognosis is poor. Among patients with diminished nerve excitability difference in threshold stimulus between the normal and affected sides appears to be a significant determinant of recovery of function. The greater the difference, the worse the prognosis.

It is suggested that the degree of excitability of the nerve on electrical stimulation may provide a clue to the actual pathological process in the nerve, that is, whether segmental demyelination or axonal degeneration.

Nerve excitability seems to be considerably influenced by the duration of paralysis. When the duration is short, nerve excitability is retained, but when it is long, response is likely to be absent.

The results of the test are correlated with classification and duration of paralysis. Recovery was best in lepromatous cases, less in borderline, and least in tuberculoid leprosy.

The treatment status of patients with reference to specific anti-leprosy drugs as well as in relation to anti-inflammatory drugs did not appear to make a significant difference to ultimate prognosis. The lessened significance of the small number of cases is emphasized.

It is suggested that this test carries prognostic significance and is a valuable aid in the assessment of chances of recovery in facial paralysis in leprosy.

\section{REFERENCES}

AULICK, L. H. (1967). The galvanic tetanus ratio test. Phys. Therapy 47, 933.

BRAND, P. W. (1964). Leprosy in Theory and Practice, 2nd ed., p. 472. Bristol: John Wright \& Sons.

CAMPBELl, E. D. R., HICKEY, R. P. and NIXON, K. H. (1962). Value of nerve excitability measurements in prognosis of facial palsy. Br. med. .J. $i, 7$.

DUCHENNE, G. B. (1872). De l'électrisation localisée. Paris: Baillière.

EDITORIAL (1967). Lepr. India 39, no. 4.

GILliatt, R. W. (1962). Electrodiagnosis and electromyography in clinical practice (The Goulstonian lecture). Br. med. J. ii, 1073.

LICHT, s. (196.2). Electrodiagnosis and Electromyography, p. 201. New Haven, Conn.: Elizabeth Licht.

MEDICAL RESEARCH COUNCIL, Special Report Series (1954). Peripheral Nerve Injuries. London.

WYNN PARRY, c. B. (1961). Electrodiagnosis. J. Bone.Jt Surg. 43 B, 222. 